\section{Breastfeeding and Hospital Infant Feeding Practices in Newfoundland, 20 Years On: More Work to Do}

\section{Dear Editor:}

Numerous studies have documented the benefits of breastfeeding for both mother and baby. ${ }^{1,2}$ Professional organizations, therefore, widely recommend exclusive breastfeeding until the age of six months, and continued breastfeeding up to 12 months and beyond as optimal infant nutrition..$^{3-7}$ Yet breastfeeding rates around the world fall alarmingly short of these goals. ${ }^{8}$

Newfoundland and Labrador, Canada's easternmost province, is no exception. In fact, a recent study based on information from $2006^{9}$ showed Newfoundland and Labrador to have the country's second-lowest breastfeeding initiation rate (75\%, compared with the national average of $90 \%)$, and its lowest rate of exclusive breastfeeding at six months ( $6 \%$, compared with the national average of $14 \%)$. A study done in Newfoundland 20 years ago provides some historical context: ${ }^{10}$ while breastfeeding initiation per se was not captured, less than half (42\%) of mothers reported breastfeeding exclusively while in hospital, 57\% were formula feeding, and 1\% were breastfeeding with formula supplementation; only $11 \%$ remained breastfeeding exclusively at six months. No published studies of current infant feeding practices in hospital are available.

Therefore, we set out to do a chart review of the question at the Janeway Children's Hospital-Health Sciences Centre in St. John's, the provincial capital (population approximately 100,000). Between June 1, 2007 and May 30, 2008, 2,550 infants were born at the hospital. Charts of live infants were randomized and the first 250 were requested from Eastern Health. Feeding information was taken from the Infant Data Flow Sheet. The research was approved by Memorial University's Human Investigations Committee (approval number 09.226), and the chart review was conducted January through July, 2010.

One hundred and seventy infants (68\%) received breast milk at least once during their admission (the criterion for breastfeeding initiation), consistent with recent national data. ${ }^{9}$ However, only $64(26 \%)$ infants received breast milk exclusively throughout their hospital admission, either directly from the breast or in expressed form; in contrast, Matthews et al. found that $42 \%$ of infants were exclusively breastfed during the 1990 s. ${ }^{10}$ We also found that breastfeeding with formula supplementation occurred with more than one third of infants $(n=89,36 \%)$; this is much higher than the $1 \%$ supplementation rate found in the Matthews et al. study. Eighty (32\%) infants were given formula exclusively from birth, and a further
17 (7\%) began with breastfeeding, but switched to exclusive formula feeding.

Though this study is somewhat limited by a small sample size, it confirmed that the rate of breastfeeding initiation in St. John's $(68 \%)$ is consistent with that reported recently from national survey data. ${ }^{9}$ However, it also provided important new information that 20 years on in Newfoundland and Labrador, in-hospital formula supplementation rates have climbed and exclusive breastfeeding rates both at discharge from hospital and at six months have in fact dropped.

While disappointing, this means that targeting hospital infant feeding practices continues to matter, and represents a real opportunity for improving maternal and child health in this province and elsewhere.

\section{Monica G. Kidd, MD, ${ }^{1}$ Kris Aubrey-Bassler, $M D^{2}$}

1. Discipline of Family Medicine, Faculty of Medicine, Memorial University, St. John's, NL 2. Primary Healthcare Research Unit, Memorial University, St. John's, NL

Correspondence: Dr. Monica Kidd, Discipline of Family Medicine, Faculty of Medicine, Memorial University, St. John's, NL A1B 3V6, Tel: 709-777-2903, Fax: 709777-7916, E-mail: monica.kidd@mun.ca

Acknowledgements: We thank Shabnam Asghari and Marshall Godwin for insight into statistical design and analysis; Serge Beaulieu, Linda Byrne, Phyllis Nagle for pulling charts; Stephanie Bennett for help with data collection; and Lorraine Burrage, Anne Drover, Janet Murphy-Goodridge and Wanda Parsons for comments on the manuscript.

\section{REFERENCES}

1. Ip S, Chung M, Raman G, Chew P, Magula N, DeVine D, et al. Breastfeeding and Maternal and Infant Health Outcomes in Developed Countries. Evidence Report/Technology Assessment No. 153. Rockville, MD: Agency for Healthcare Research and Quality, 2007.

2. Kramer MS, Kakuma R. Optimal duration of exclusive breastfeeding. Cochrane Database Syst Rev 2002;1:CD003517.

3. World Health Organization/UNICEF. Innocenti Declaration on the Protection, Promotion and Support of Breastfeeding. Florence, Rome: UNICEF, 1990.

4. American College of Nurse-Midwives, Division of Women's Health Policy and Leadership. Position statement: Breastfeeding, 2004. Available at: http://www.midwife.org/siteFiles/position/Breastfeeding_05.pdf (Accessed June 28, 2012).

5. Boland M. Exclusive breastfeeding should continue to six months. Pediatr Child Health 2005;10(3):148.

6. American Academy of Family Physicians. Breastfeeding (policy statement), 2007. Available at: http://www.aafp.org/online/en/home/policy/policies/b/ breastfeedingpolicy.html (Accessed June 28, 2012).

7. U.S. Department of Health and Human Services. The Surgeon General's Call to Action to Support Breastfeeding. Washington, DC: U.S. Department of Health and Human Services, Office of the Surgeon General, 2011.

8. World Health Organization. Global Strategy for Infant and Young Child Feeding. Geneva, Switzerland: WHO, 2003.

9. Chalmers B, Levitt C, Heaman M, O’Brien B, Sauve R, Kaczorowski J. Breastfeeding rates and hospital breastfeeding practices in Canada: A national survey of women. Birth 2009;36:122-32.

10. Matthews MK, Webber K, McKim E, Banoub-Baddour S, Laryea M. Infant feeding practices in Newfoundland and Labrador. Can J Public Health 1995;86:296300 . 